\title{
HUBUNGAN PENGETAHUAN DAN SIKAP BIDAN TENTANG RETENSIO DENGAN PENATALAKSANAAN MANUAL PLASENTA DI WILAYAH KERJA PUSKESMAS HUTA RAKYAT SIDIKALANG
}

\author{
Effendi Sianturi \\ Jurusan Kebidanan Poltekkes Kemenkes Medan
}

\begin{abstract}
Abstrak
Penatalaksanaan manual plasenta merupakan tindakan operasi kebidanan untuk melahirkan retensio plasenta. Rentensio plasenta dapat menyebabkan perdarahan, perdarahan merupakan penyebab nomor satu (40\%-60\%) kematian ibu melahirkan. Menurut WHO dilaporkan bahwa 15-20\% kematian ibu di sebabkan oleh retensio plasenta dan insidennya adalah $1 \%$ untuk setiap kelahiran. Jenis penelitian ini adalah Analitik Korelasi dengan menggunakan metode pendekatan Cross Sectional. Penelitian ini dilaksanakan di wilayah kerja Puskesmas Huta Rakyat Sidikalang, dari bulan Maret sampai dengan Juli 2015. Populasi dan sampel dalam penelitian ini semua bidan yang mempunyai praktek sendiri/klinik yang berada di wilayah kerja Puskesmas Huta Rakyat Sidikalang, sampel diambil dengan cara Total Sampling dengan jumlah sampel 35 orang. Penelitian ini menggunakan uji Chi Square dengan $\alpha=0.05$. Hasil penelitian menunjukkan bahwa ada hubungan pengetahuan bidan tentang retensio plasenta dengan penatalaksanaan manual plasenta dengan nilai $\rho=0,001(\rho<0,05)$, dan ada hubungan sikap bidan terhadap retensio plasenta dengan penatalaksanaan manual plasenta di dengan nilai $\rho=0,001(\rho<0,05)$. Diharapkan pada bidan yang mempunyai pengetahuan dan sikap yang kurang mengerti tentang retensio plasenta dan penatalaksanaan manual plasenta agar lebih aktif dan tanggap dalam mendapatkan informasi dari berbagai media seperti buku, internet, dan pengalaman dari bidan yang lebih senior sehingga bidan dapat mengambil keputusan dengan tepat dan tidak tidak terjadi keterlambatan dalam pelaksanaan asuhan kebidanan pada ibu bersalin dengan retensio plasenta.
\end{abstract}

Kata kunci : Pengetahuan, Sikap, Retensio Plasenta, Penatalaksanaan Manual Plasenta

\section{PENDAHULUAN}

Retensio plasenta (placental retention) merupakan plasenta yang belum lahir dalam setengah jam setelah janin lahir. Menurut Prabowo (2012) plasenta yang belum lahir dapat menyebabkan komplikasi dalam persalinan dan akan memerlukan transfusi darah, terjadinya multiple organ failure yang berhubungan dengan kolaps sirkulasi dan penurunan perfusi organ, sepsis dan terjadinya histerektomi dan hilangnya potensi untuk memiliki anak selanjutnya.

Rentensio plasenta dapat menyebabkan perdarahan, perdarahan merupakan penyebab nomor satu (40\%-60\%) kematian ibu melahirkan. Menurut WHO dilaporkan bahwa 15-20\% kematian ibu di sebabkan oleh retensio plasenta dan insidennya adalah $1 \%$ untuk setiap kelahiran. Dibandingkan dengan resiko-resiko lain dari persalinan retensio plasenta merupakan salah satu penyebab perdarahan post partum yang dapat mengancam jiwa ibu dimana perdarahan yang hebat akan cepat dan tidak mendapat perawatan medis yang tepat akan mempercepat kematian (Pratiwi, 2012).

Berdasarkan data WHO (2010) rasio kematian ibu selama kehamilan dan melahirkan atau dalam 42 hari setelah melahirkan adalah per 100.000. Angka kematian ibu di negara ASEAN seperti Thailand berkisar antara 32 36/100.000, dan di Malaysia 14-68/100.000. Sedangkan di Indonesia berkisar antara 140-380/100.000, menurut survei demografi dan kesehatan Indonesia tahun 2007 menyebutkan bahwa AKI di Indonesia untuk periode lima tahun (2003-2007) sebesar 228/100.000 kelahiran hidup (Pratiwi, 2010).

Retensio plasenta terjadi pada 3\% kelahiran pervaginam dan $15 \%$ kasus retensio plasenta dialami oleh ibu dengan riwayat retensio plasenta pada persalinan sebelumnya. Dari penelitian Marhadia pada tahun 2005-2007 di RSUP H.Adam Malik Medan terdapat $76(11,5 \%)$ kasus retensio plasenta dari 661 persalinan spontan, dan terdapat $82(7,7 \%)$ kasus retensio plasenta dari 1056 persalinan spontan di RSUP Pirngadi Medan (Harmia, 2010).

Profesi bidan mampu mengenali dan mampu memberikan pertolongan pertama, termasuk manual plasenta dan penanganan perdarahan sesuai dengan indikasi. Sehingga telah didapati hasilnya berupa penurunan kejadian perdarahan hebat dan mendapatkan penanganan yang cepat dan tepat dan penyelamatan ibu Sehingga bidan harus benar-benar mampu melakukan penatalaksanaan manual plasenta, (Ikatan Bidan Indonesia, 2010). 
Melalui wawancara yang di lakukan penulis terhadap 6 bidan pada saat survey awal di lapangan penulis menemukan pengakuan bahwa dari 6 bidan tersebut hanya 2 orang saja yang berani melakukan penatalaksanaan manual plasenta, semantara ke 4 bidan yang lainnya mengakui ragu-ragu dalam melakukanya. Hal ini di dukung oleh adanya data yang di temukan di RSUD sidikalang bahwa kasus retensio plasenta merupakan kasus yang paling sering di rujuk oleh bidan setempat, situasi seperti di atas menghasilkan pertanyaan adakah perselisihan antara pengetahuan, setiap bidan tentang retensio plasenta terhadap penatalaksanaan retensio plasenta.

Berdasarkan latar belakang masalah diatas penulis tertarik melakukan penelitian dengan judul "Hubungan pengetahuan dan sikap bidan tentang retensio plasenta dengan pelaksanaan manual plasenta Pada Bidan di wilayah kerja Puskesmas huta rakyat Sidikalang Tahun 2015".

\section{Rumusan Masalah}

Perumusan masalah dalam penelitian ini adalah bagaimanakah hubungan pengetahuan dan sikap bidan tentang retensio plasenta dengan pelaksanaan manual plasenta di wilayah kerja puskesmas huta rakyat Sidikalang Tahun 2015.

\section{Tujuan Penelitian \\ Tujuan Umum}

Untuk mengetahui hubungan pengetahuan dan sikap tentang retensio plasenta dengan pelaksanaan manual plasenta di wilayah kerja puskesmas huta rakyat Sidikalang Tahun 2015.

\section{Tujuan Khusus}

1. Untuk mengetahui hubungan pengetahuan dengan pelaksanaan manual plasenta di wilayah kerja Puskesmas huta rakyat Sidikalang Tahun 2015.

2. Untuk mengetahui hubungan sikap dengan pelaksanaan manual plasenta di wilayah kerja Puskesmas huta rakyat Sidikalang Tahun 2015

3. Untuk mengetahui pelaksanaan manual plasenta di wilayah kerja Puskesmas huta rakyat Sidikalang Tahun 2015

\section{Hipotesa Penelitian}

1. Adanya hubungan antara pengetahuan tentang retensio plasenta dengan pelaksanaan manual plasenta di wilayah kerja Puskesmas huta rakyat Sidikalang Tahun 2015.

2. Adanya hubungan antara sikap tentang retensio plasenta dengan pelaksanaan manual plasenta Pada Bidan di wilayah kerja Puskesmas huta rakyat Sidikalang Tahun 2015.

\section{METODE PENELITIAN}

\section{Jenis Penelitian}

Penelitian ini menggunakan jenis penelitian analitik korelasi dengan metode pendekatan cross sectional yang bertujuan untuk mengetahui Hubungan pengetahuan dan sikap bidan tentang retensio plasenta dengan pelaksanaan manual plasenta Pada Bidan di wilayah kerja Puskesmas Huta Rakyat Sidikalang Tahun 2015.

\section{Lokasi dan Waktu Penelitian \\ Lokasi Penelitian}

Penelitian ini dilakukan di wilayah kerja

Puskesmas Huta Rakyat Sidikalang.

\section{Waktu Penelitian}

Penelitian dimulai pada bulan Maret sampai dengan Juli 2015.

\section{Populasi dan Sampel Populasi}

Populasi dalam penelitian ini adalah semua bidan yang mempunyai praktek sendiri/klinik yang berada di wilayah kerja Puskesmas Huta Rakyat Sidikalang.

\section{Sampel}

Cara pengambilan sampel dalam penelitian ini adalah dengan mengunakan teknik total sampling yaitu sebanyak 35 orang yang diperoleh dari Puskesmas.

\section{Metode Pengumpulan Data}

Pengumpulan data pada penelitian ini dilakukan dengan dua cara yaitu:

\section{Data primer}

Yaitu data yang langsung diperoleh dari responden dengan menggunakan kuesioner yang dijawab langsung oleh responden untuk menilai variabel penelitian.

\section{Data Sekunder}

Data skunder diperoleh dari Dinas Kesehatan Kabupaten Dairi mengenai jumlah tenaga bidan yang ada di wilayah kerja Puskesmas Huta Rakyat Sidikalang.

\section{Metode Analisa Data}

Data dianalisa dengan uji statistik Chi-Square

\section{Hasil Penelitian}

\section{Gambaran Umum Lokasi Penelitian}

Wilayah kerja Puskesmas Huta Rakyat Sidikalang yang berada di Desa Kalang Huta Gambir barat Kecamatan Sidikalang Batang Beruh memiliki luas wilayah $11.9 \mathrm{Km}^{2}$. Desa ini memiliki jumalah penduduk sebanyak 1.442 jiwa dengan jumlah lansia 332 jiwa.Wilayah kerja Puskesmas huta rakyat Sidikalang terdiri dari kelurahan yaitu : Belang malung, Kota, Desa kalang, Huta gambir, Huta rakyat.

Wilayah kerja Puskesmas Huta Rakyat adalah sebangai barikut :Sebelah barat berbatasan dengan : Berampu, Sebelah timur berbatasan dengan : Kecematan sidikalang Batang beruh, Sebelah utara berbatasan dengan : Siempat nempuh (Km 11), Sebelah selatan berbatasan dengan : Kabupaten pak-pak barat. 
Karakteristik Responden

Tabel 4.1

Distribusi Frekuensi Karakteristik Responden di Wilayah Kerja

Puskesmas Huta Rakyat SidikalangTahun 2015

\begin{tabular}{llll}
\hline No & Karakteristik & Frekuensi & Persentasi (\%) \\
\hline $\mathbf{1}$ & Kelompok Umur & & 57.1 \\
& 25-32 Tahun & 20 & 25.7 \\
& $33-40$ Tahun & 9 & 17.7 \\
& $41-48$ Tahun & 6 & $\mathbf{1 0 0}$ \\
\hline & Total & $\mathbf{3 5}$ & \\
\hline $\mathbf{2}$ & Pendidikan & & 82.9 \\
& D-III Kebidanan & 29 & 17.1 \\
& D-IV Kebidanan & 6 & $\mathbf{1 0 0}$ \\
& Total & $\mathbf{3 5}$ & 25.7 \\
\hline $\mathbf{3}$ & Lama Pengalaman Kerja & & 40.0 \\
\hline & >10 Tahun & 9 & 34.3 \\
& 5-10 Tahun & 14 & $\mathbf{1 0 0}$ \\
& < 5 Tahun & 12 & \\
\hline
\end{tabular}

4.1.3 Analisa Univariat

1. Pengetahuan Bidan Tentang Retensio Plasenta

Tabel 4.2

Distribusi Frekuensi Pengetahuan Dan Sikap Bidan Tentang Retensio Plasenta di Wilayah Kerja Puskesmas Huta Rakyat Sidikalang Tahun 2015

\begin{tabular}{l|l|l|l}
\hline No & Pengetahuan & Frekuensi & Persentasi (\%) \\
\hline 1 & Baik & 13 & 37.1 \\
2 & Cukup & 19 & 54.3 \\
3 & Kurang & 3 & 8.6 \\
\hline & Total & 35 & 100 \\
\hline
\end{tabular}

2. Sikap Bidan Terhadap Retensio Plasenta

Tabel 4.3

Distribusi Frekuensi Sikap Bidan Terhadap Retensio Plasenta di Wilayah Kerja Puskesmas Huta Rakyat Sidikalang Tahun 2015

\begin{tabular}{l|l|l|l}
\hline No & Sikap & Frekuensi & Persentasi (\%) \\
\hline 1 & Baik & 32 & 91.4 \\
2 & Tidak Baik & 3 & 8.6 \\
\hline & Total & 35 & 100 \\
\hline
\end{tabular}

Penatalaksanaan Manual Plasenta

Tabel 4.4

Distribusi Frekuensi Penatalaksanaan Manual Plasenta di Wilayah Kerja Puskesmas Huta Rakyat SidikalangTahun 2015

\begin{tabular}{l|l|l|l}
\hline No & Penatalaksanaan Manual Plasenta & Frekuensi & Persentasi (\%) \\
\hline 1 & Sesuai Standar & 27 & 77.1 \\
2 & Tidak Sesuai Standar & 8 & 22.9 \\
\hline & Total & 35 & 100 \\
\hline
\end{tabular}


4.1.4 Analisa Bivariat

Tabel 4.5

Hasil Uji Statistik Hubungan Pengetahuan Bidan Dengan Penatalaksanaan Manual Plasenta di Wilayah Kerja Puskesmas Huta Rakyat Sidikalang

Tahun 2015

\begin{tabular}{|c|c|c|c|c|c|c|c|c|c|}
\hline \multirow{3}{*}{ No } & \multirow{3}{*}{$\begin{array}{c}\text { Pengetahuan Bidan } \\
\text { Tentang Retensio Plasenta }\end{array}$} & \multicolumn{4}{|c|}{$\begin{array}{c}\text { Penatalaksanaan Manual } \\
\text { Plasenta }\end{array}$} & \multicolumn{2}{|c|}{ Total } & \multirow[t]{3}{*}{ Df } & \multirow[t]{3}{*}{$\rho$} \\
\hline & & \multicolumn{2}{|c|}{$\begin{array}{l}\text { Sesuai } \\
\text { Standar }\end{array}$} & \multicolumn{2}{|c|}{$\begin{array}{c}\text { Tidak Sesuai } \\
\text { Standar }\end{array}$} & \multirow[b]{2}{*}{$\mathbf{n}$} & \multirow[b]{2}{*}{$\%$} & & \\
\hline & & $\mathbf{n}$ & $\%$ & $\mathbf{n}$ & $\%$ & & & & \\
\hline 1 & Baik & 13 & 37.1 & 0 & 0 & 13 & 37.1 & 2 & 0,001 \\
\hline 2 & Cukup & 14 & 40.0 & 5 & 14.3 & 19 & 54.3 & & \\
\hline 3 & Kurang & 0 & 0 & 3 & 8.6 & 3 & 8.6 & & \\
\hline & Total & 27 & 77.1 & 8 & 22.9 & 35 & 100 & & \\
\hline
\end{tabular}

Tabel 4.6

Hasil Uji Statistik Hubungan Sikap Bidan Terhadap Retensio Plasenta Dengan Penatalaksanaan Manual Plasenta di Wilayah Kerja

\begin{tabular}{|c|c|c|c|c|c|c|c|c|c|}
\hline \multirow{3}{*}{ No } & \multirow{3}{*}{$\begin{array}{c}\text { SikaBidan Terhadap } \\
\text { Retensio Plasenta }\end{array}$} & \multicolumn{4}{|c|}{$\begin{array}{c}\text { Penatalaksanaan Manual } \\
\text { Plasenta }\end{array}$} & \multirow{2}{*}{\multicolumn{2}{|c|}{ Total }} & \multirow{3}{*}{ Df } & \multirow{3}{*}{$\boldsymbol{\rho}$} \\
\hline & & \multicolumn{2}{|c|}{ Sesuai Standar } & \multicolumn{2}{|c|}{$\begin{array}{c}\text { Tidak Sesuai } \\
\text { Standar }\end{array}$} & & & & \\
\hline & & $\mathbf{n}$ & $\%$ & $\mathbf{N}$ & $\%$ & $\mathbf{n}$ & $\%$ & & \\
\hline 1 & Baik & 27 & 77.1 & 5 & 14.3 & 32 & 91. & 2 & 0,001 \\
\hline \multirow[t]{2}{*}{2} & Tidak Baik & 0 & 0 & 3 & 8.6 & 3 & 8.6 & & \\
\hline & Total & 27 & 77.1 & 8 & 22.9 & 35 & 10 & & \\
\hline
\end{tabular}

\section{PEMBAHASAN}

1. Pengetahuan Bidan Tentang Retensio Plasentadi Wilayah Kerja Puskesmas Huta Rakyat Sidikalang Tahun 2015

Berdasarkan hasil penelitian yang dilakukan pada 35 orang bidan yang menjadi responden didapat hasil bahwa pengetahuan bidan tentang retensio plasenta adalah pengetahuan baik sebanyak 13 orang (37.1\%), pengetahuan cukup sebanyak 19 orang $(54.3 \%)$, pengetahuan kurang sebanyak 3 orang $(8.6 \%)$.

Responden yang berpengetahuan baik sebanyak 22 orang $(33.8 \%)$ umumnya berpendidikan D-III Kebidanan sebanyak7 orang (20.0\%), dan seluruh responden yang berpendidikan D-IV Kebidanan sebanyak 6 orang (17.1\%), Responden yang berpengetahuan cukup adalah memiliki tingkat pendidikan D-III Kebidanan sebanyak 19 orang $(54.3 \%)$, sedangkan responden yang berpengetahuan kurang juga memiliki tingkat pendidikan D-III Kebidanan sebanyak 3 orang $(8.6 \%)$. Hal diatas sesuai dengan teori yang diungkapkan oleh Notoatmodjo (2010), yaitu tingkat pendidikan turut pula menentukan mudah tidaknya seseorang menyerap dan memahami informasi maupun pengetahuan yang mereka peroleh, pada umumnya semakin tinggi pendidikan seseorang makin semakin baik pula pengetahuannya.

Menurut Notoatmodjo (2010), perubahan perubahan perilaku dalam seseorang dapat diketahui melalui persepsi. Persepsi adalah pengalaman yang dihasilkan melalui indra penglihatan, pendengaran, penciuman, dan sebagainya. Setiap orang memiliki persepsi yang berbeda meskipun objeknya sama, dalam hal ini pendidikan merupakan salah satu faktor yang sangat penting dalam perubahan perilaku. Pendidikan merupakan suatu intervensi atau upaya yang ditujukan kepada perilaku agar perilaku tersesbut kondusif untuk kesehatan. Dengan kata lain pendidikan mengupayakan agar perilaku individu, kelompok dan masyarakat mempunyai pengaruh positif terhadap pemeliharaan dan peningkatan kesehatan.

Jika dilihat dari segi usia, dari 13 orang (37.1\%) responden yang memiliki pengetahuan baik mayoritas berada pada usia 41 - 48 tahun sebanyak 6 orang $(17.1 \%)$, responden yang memiliki pengetahuan cukup mayoritas berada pada usia 25 - 32 tahun sebanyak 13 orang (37.1\%), dan responden yang memiliki pengetahuan kurang mayoritas berada pad usia 25 - 32 tahun sebanyak 3 orang $(8.6 \%)$. Menurut Notoatmodjo (2010) daya ingat seseorang itu salah satunya dipengaruhi oleh umur. Hal ini sesuai juga denga teori yang diungkapkan oleh Wawan dan Dewi (2010) bahwa semakin cukup umur, tingkat kematangan dan kekuatan seseorang akan lebih matang dalam berpikir dan bekerja. Maka menurut asumsi peneliti semakin matangnya usia memungkinkan semakin banyak pengetahuan yang diperolehnya tentang retensio plasenta.

Dari hasil penelitian jika dilihat dari lama pengalaman kerja, mayoritas lama pengalaman kerja adalah $5-10$ tahun sebanyak 14 orang (40.0\%). Responden yang berpengetahuan baik umumnya memiliki pengalaman kerja selama $>10$ tahun sebanyak 7 orang $(20.0 \%)$, dan pengalaman kerja selama $5-10$ tahun sebanyak 6 orang (17.1\%), responden yang berpengetahuan cukup umumnya 
memiliki pengalaman kerja $<5$ tahun sebanyak 9 orang (25.7\%), yang memiliki pengalaman kerja selama 5 10 tahun sebanyak 8 orang $(22.9 \%)$ dan pengalaman kerja $>10$ tahun sebanyak 2 orang $(5.7 \%)$, sedangkan responden yang berpengetahuan kurang seluruhnya memiliki pengalaman kerja $<5$ tahun sebanyk 3 orang $(8.6 \%)$. Hal ini sesuai dengan teori yang diungkapkan oleh Harahap (2010) bahwa semakin lama bekerja maka akan memiliki pengalaman yang merupakan guru paling baik.

Semakin lama bekerja maka semakin banyak pengalaman dan semakin banyak kasus yang ditangani oleh bidan, maka bidan tersebut akan semakin mahir dan terampil dalam menyelesaikan pekerjaan. Kepercayaan masyarakat lebih cenderung kepada bidan yang telah lama bekerja, karena mereka menganggap bidan yang sudah lam bekerja sudah memiliki pengalaman ( Harahap, 2010).

\section{Sikap Bidan Terhadap Retensio plasenta Wilayah Kerja Puskesmas Huta Rakyat Sidikalang Tahun 2015}

Berdasarkan hasil penelitian yang dilakukan pada 35 orang bidan yang menjadi responden didapat hasil bahwa sikap bidan terhadap retensio plasenta adalah baik sebanyak 32 orang $(91.4 \%)$, sikap tidak baik sebanyak 3 orang (8.6\%).Jika dilihat dari segi pengetahuan, sebagian besar responden yang berpengetahuan baik memiliki sikap yang baik sebanyak 13 orang $(37.1 \%)$, dan yang bepengetahuan cukup juga memiliki sikap yang baik sebanyak 19 orang (54.3\%), sedangkan responden yang berpengetahuan kurang seluruhnya memiliki sikap yang tidak baik sebanyak 3 orang $(8.6 \%)$.

Menurut Notoatmodjo (2010) menyatakan bahwa sikap merupakan reaksi atau respon yang masih tertutup dari seseorang terhadap stimulus atau objek. Pengetahuan atau kognitif merupakan domain yang sangat penting untuk terbentuknya tindakan/ sikap seseorang.

Tingkat pengetahuan dan sikap sangatlah mempengaruhi kemampuan seseorang. Menurut ahli psikologis sosial sikap merupakan kesiapan atau kesediaan untuk bertindak dan bukan merupakan pelaksanaan motif tertentu. Sikap belum merupakan suatu tindakan atau aktivitas, akan tetapi merupakan predisposisi tindakan suatu perilaku (Notoatmodjo, 2010).

Menurut Soenaryo (2007), perilaku manusia saling berkaitan,perilakusekarang adalah kelangsungan dari perilaku yang lalu, dalam kata lain perilaku manusia terjadi secara kesinambungan bukan secara serta merta. Oleh sebab itu dapat diasumsikan bahwa dengan semakin sering melakukan suatu perilaku makasikap seseorang tersebut untuk melakukan perilaku yang sama juga akan semakin baik. Demikian juga menurut asumsi peneliti bahwa sikap bidan untuk menerapkan standarasuhan persalinan, semakin sering bidan melakukan asuhan persalinan dengan maslah retensio plasenta maka akan mewujudkan sikap untuk menerapkan standar penatalaksanaan asuhan persalinan adalah semakin baik.

Proses pembentukan sikap adalah adanya pengaruh orang lain terutama guru dan rekan-rekannya. Kemampuan berfikir, kemampuan memilih danfaktorfaktor intrinsik lainnya yang mempengaruhi sikap seseorang terhadap peristiwa-peristiwa. Sikap yang seharusnya dimiliki oleh seorang bidan pada ibu bersalin dengan retensio plasenta adalah memperhatikan keadaan umum penderita, apakah keadaan anemis, jumlah perdarahan, pemantauan tekanan darah, nadi dan suhu, pemeriksaan kontraksi dan tinggi fundus uteri, mengetahui keadaan plasenta, apakah plasenta inkaserata, melakukan pelepasan plasenta/ manual plasenta, memasang infus dan memberikan cairan pengganti (Rohani dkk, 2011).

\section{Penatalaksanaan Manual Plasenta di Wilayah Kerja Puskesmas Huta Rakyat Sidikalang Tahun 2015}

Berdasarkan hasil penelitian distribusi frekuensi penatalaksanaan manual plasenta yang dapat dilihat pada tabel 4.4 bahwa bidan yang melakukan penatalaksanaan manual plasenta ysesuai standar sebanyak 27 orang (77.1\%) dan yang tidak sesuai satandar sebanyak 8 orang $(22.9 \%)$.

Menurut Rukiyah \& Yulianti (2010) retensio plasenta adalah terlambatnya kelahiran plasenta selama setengah jam setelah persalinan bayi. Retensio plasentadalam rahim akan menghambat kontraksi dan retraksi uterus sehingga apabila plasentasudah dilahirkan dengan cara plasenta manual maka akan mengalami kelelahan sehingga menimbulkan atonia uteri atauterjadi perdarahan pada daerah tersebut. Sedangkan apabila pada retensio plasentadengan adanya sebagian daerah yang sudah terlepas maka akan menyebabkan perdarahan karena adanya sinus- sinus darah yang terbuka pada saat uterus berkontraksi.

Menurut penelitianoleh Soufyan dan Wawang (2008) yang mendapatkan kejadian perdarahan postpartum akibat retensio plasenta paling banyak pada paritas $\geq 4$ sebesar $25,5 \%$,sedangkan hasil penelitian yang dilakukan oleh Santoso (2003) kejadian retensio plasenta paling banyak pada paritas 6sebesar $6,85 \%$. Sesuai dengan teori bahwa kejadian retensio plasenta lebih tinggi pada grandemultipara. Hal ini di hubungkan dengan kontraksi dari rahim yang kurangbagus karena dinding uterus yang sangat teregang dan banyak parutan bekasimplantasi plasenta pada persalinan sebelumnya. Tindakan segera yangharus dilakukan apabila terjadi retensioplasenta dan menimbulkan perdarahan adalah melakukan pengeluaran plasenta secara manual/ manual plasenta (Farid, 2013).

Tindakan manual plasenta merupakan tindakan operasi kebidanan untuk melahirkan retensio plasenta. Tehnik manual plasenta tidaklah sukar, tapi harus diperkirakan bagaimana persiapan agar tindakan tersebut dapat menyelamatkan jiwa penderita (Rohani dkk, 2011). 
Menurut Rohani dkk (2011), dalam kasus perdarahan post partum karena retensio plasenta, antisipasi yang dilakukan adalah pemeriksaan keadaan umum ibu, kesadaran, tanda-tanda vital (tekanan darah, nadi, respirasi, dan suhu), tonus uterus, dan estimasi banyaknya darah yang sudah keluar, kemudian dilakukan pemberian oksitosin 20 unit dalam $500 \mathrm{cc}$ NS/RL dengan tetesan 40 tetes permenit dan pemberian antibiotik profilaksis (ampicilin 2 gram IV/oral + metronidazol 1 gram per oral) serta dilakukan plasenta manual.

Bidan merupakan tenaga andalan masyarakat untuk dapat memberikan pertolongan kebidanan, sehingga dapat menurunkan angka kesakitan ataukematian ibu maupun perinatal. Dalam menghadapi perdarahan pada kehamilan, sikap bidan yang paling utama adalah melakukan rujukan kerumah sakit. Dalam melakukan rujukan diberikan pertolongan darurat adalah Pemasangan infus, tanpa melakukan pemeriksaan dalam. Diantar petugas yang dapat memberikan pertolongan, mempersiapkan donor dari keluarga atau masyarakat, menyertakan keterangan tentang apa yang telah dilakukan untuk memberikan pertolongan pertama.

\section{Analisa Bivariat \\ Hubungan Pengetahuan Bidan Tentang Retensio Plasenta Dengan Penatalaksanaan Manual Plasenta di Wilayah Kerja Puskesmas Huta Rakyat Sidikalang Tahun 2015}

Berdasarkan hasil penelitian menunjukkan bahwa responden yang memiliki pengetahuan baik sebanyak 13 orang $(37.1 \%)$, selurunya dalam melakukan penatalaksanaan manual plasenta adalah sesuai standar, dan responden yang memiliki pengetahuan cukup, dimana dalam melakukan penatalaksanaan manual plasenta yang sesuai standar sebanyak 14 orang $(40.0 \%)$ dan yang tidak sesuai standar sebanyak 5 orang (14.3\%), sedangkan responden yang memiliki pengetahuan kurang seluruhnya dalam melakukan penatalaksanaan manual plasenta adalah tidak sesuai dengan standar sebanyak 3 orang (8.6\%). Dari hasil uji statistik dengan menggunakan uji chi square, diperoleh hasil bahwa nilai $\rho=0,001(\rho<0,05)$ artinya ada hubungan antara pengetahuan bidan tentang retensio plasenta dengan penatalaksanaan manual plasenta.

Menurut Notoatmodjo (2010), pengetahuan atau kognitif merupakan dominanyang sangat penting dalam membentuk tindakan seseorang (over behavior).Tindakan petugas kesehatan dalam menangani pasien ditentukan oleh pengetahuan tenaga kesehatan tersebut. Asumsi peneliti menyatakan bahwa seorang bidan yang telah mengetahui tentang retensio plasenta, maka akan membuat bidan mengerti tentang penanganan retensio plasenta dan penatalaksanaan manual plasenta.

Meliono,dkk (2007) menyatakan bahwa pengetahuan merupakan hal penting bagi bidan dalam rangka mengaplikasikan keilmuannya di liongkungan
masyarakat.Pengetahuan adalah berbagai gejala yang ditemui dan diperoleh manusia melaluipengamatan inderawi. Pengetahuan muncul ketika seseorang menggunakan inderaatau akal budinya untuk mengenali kejadian tertentu yang belum pernah dilihatatau dirasakan sebelumnya.

Menurut Petra (2008) secara psikologis kemampuan atau ability terdiri dari knowledge dan skill. Hal ini menunjukkan bahwa tingkat pengetahuan dan tingkat kemampuan seseorang saling berkaitan dan saling mempengaruhi satu sama lain.Seseorang dengan tingkat pengetahuan yang kurang, relatif tidak dapat melakukan praktik secara maksimal. Pernyataan tersebut terbukti dari hasil penelitian yang menyatakan bahwa dari 3 responden dengan tingkat pengetahuan kurang, terdapat 3 responden yang termasuk kategori tidak kompeten dalam penatalaksanaan manual plasenta.

Dengan ini peneliti dapat mengasumsi bahwa mayoritas bidan memiliki pengetahuan yang cukup tentang penatalaksanaan manual plasenta. Walaupun masih ada 3 responden yang bepengetahuan kurang hal ini disebabkan karena bidan belum banyakmengikuti proses tentang penatalaksanaan manual plasenta dan pengalaman kerja yang < 5 tahun serta tidak mendapatkan informasi yang diperoleh dari buku, media massa ataupun internet tentang penatalaksanaan manual plasenta, sehingga bidan akhirnya merasa raguragu dalam penatalaksanaan manual plasenta. Oleh karena itu itu bidan harus mempunyai pengetahuan yang baik dan mencari informasi- informasi yang baru agar bisamenerapkan penatalaksanaan manual plasenta dalam persalinan yang sesuai dengan standart.

\section{Hubungan Sikap Bidan Terhadap Retensio Plasenta Dengan Penatalaksanaan Manual Plasentadi Wilayah Kerja Puskesmas Huta Rakyat Sidikalang Tahun 2015}

Berdasarkan hasil penelitian menyatakan bahwa sikap responden terhadap retensio plasenta mayoritas memiliki sikap yang baik sebanyak 32 orang (91.4\%). Jika dihubungkan dengan penatalaksanaan manual plasenta, dimana sikap bidan yang baik terhadap retensio plasenta mayoritas dalam melakukan penatalaksanaan manual plasenta sesuai standar sebanyak 27 orang $(77.1 \%)$ dan yang tidak sesuai dengan standar sebanyak 5 orang $(14.3 \%)$. Sedangkan sikap bidan yang tidak baik terhadap tretensio plasenta seluruhnya dalam melakukan penatalaksanaan manual plasenta adalah tidak sesuai dengan standar sebanyak 3 orang (8.6\%). Dari hasil uji statistik dengan menggunakan uji chi square, diperoleh hasil bahwa nilai $\rho=0,001(\rho<0,05)$ artinya ada hubungan antara sikap bidanterhadap retensio plasenta dengan penatalaksanaan manual plasenta.

Sikap adalah determinan perilaku, karena mereka berkaitan dengan persepsi, kepribadian dan motivasi. Sebuah sikap merupakan suatu keadaan siap mental, yangdipelajari dan diorganisasi menurut pengalaman dan yang menyebabkan timbulnya 
pengaruh khusus atau reaksi seseorang terhadap orangorang, objek-objekdan situasi situasi dengan siapa dia berhubungan (Winardi, 2007).

Menurut Winardi (2007) sikap dalam upaya penanganan adalah pengembangan ide-ide tentang rincian masalah yang terkandung dalam individu, penjelajahan lebih lanjut tentang segala beluk masalah, mengusahakan cara-cara untuk mengatasi atau memecahkan sumber pokok permasalahan. Upaya penanganan belum merupakan suatu tindakan atau aktivitas akan tetapi merupakan pengembangan ide dari suatu perilaku.

Dengan ini peneliti dapat mengasumsi bahwa sikap bidan banyak yangberprilaku baik namun masih ada bidan yang dalam penatalaksanaan manual plasenta tidak sesuai dengan standar, hal itu disebabkan karena banyak bidan DIII yang dipengaruhi oleh keterbatasan waktu bekerja, keterbatasan alat, dan yang paling utama disebabkan karena kurangnya minat daribidan itu sendiri. Hal ini masih banyak bidan DIII dapat dipengaruhi oleh sikapnya yang kurang memahami dan ketinggalan informasi, berita, bahkan jarang mengikuti pelatihan- pelatihan serta pengalaman kerja yang masih baru- baru.

Oleh karena itu diharapkan pada bidan yang mempunyai pengetahuan dan sikap yang kurang mengerti tentang retensio plasenta dan penatalaksanaan manual plasenta agar lebih aktif dan tanggap dalam mendapatkan informasi dari berbagai media seperti buku, internet, dan pengalaman dari bidan yang lebih senior sehingga bidan dapat mengambil keputusan dengan tepat dan tidak tidak terjadi keterlambatan dalam pelaksanaan asuhan kebidanan pada ibu bersalin dengan retensio plasenta.

\section{KESIMPULAN DAN SARAN}

\section{Kesimpulan}

1. Pengetahuan bidan tentang retensio plasenta di wilayah kerja Puskesmas Huta Rakyat Sidikalang Tahun 2015 mayoritas berpengetahuan cukup yaitu 19 orang $(54.3 \%)$.

2. Sikap bidan terhadap retensio plasenta di wilayah kerja Puskesmas Huta Rakyat Sidikalang Tahun 2015 mayoritas baik 32 orang $(91.4 \%)$.

3. Penatalaksanaan manual plasenta di wilayah kerja Puskesmas Huta Rakyat Sidikalang Tahun 2015 mayoritas adalah sesuai standar sebanyak 27 orang (77.1\%).

4. Ada hubungan pengetahuan bidan tentang retensio plasenta dengan penatalaksanaan manual plasenta di wilayah kerja Puskesmas Huta Rakyat Sidikalang Tahun 2015 dengan nilai $\rho=0,001(\rho<0,05)$.

5. Ada hubungan sikap bidan terhadap retensio plasenta dengan penatalaksanaan manual plasenta di wilayah kerja Puskesmas Huta Rakyat Sidikalang Tahun 2015 dengan nilai $\rho=0,001(\rho<0,05)$.

\section{Saran}

1. Bagi bidan

Diharapkan pada bidan yang mempunyai pengetahuan dan sikap yang kurang mengerti tentang retensio plasenta dan penatalaksanaan manual plasenta agar lebih aktif dan tanggap dalam mendapatkan informasi dari berbagai media seperti buku, internet, dan pengalaman pelatihan dari bidan yang lebih senior sehingga bidan dapat mengambil keputusan dengan tepat dan tidak terjadi keterlambatan dalam pelaksanaan asuhan kebidanan pada ibu bersalin dengan retensio plasenta.

2. Bagi peneliti selanjutnya

Agar lebih selektif dalam memilih responden dengan cara melihat faktor-faktor yang mempengaruhi.

\section{DAFTAR PUSTAKA}

Abdat, 2010. Hubungan Antara Paritas Ibu dengan Plasenta Previa di Rumah Sakit Dr. Moewardi Surakarta, Skripsi Universitas Sebelas Maret, Sumber : http://www. http://eprints.uns.ac.id.

Antaranews, 2010. Penurunan Angka Kematian Ibu, sumber : http

://www.antarnews.com

Farid. 2013. Jurnal Pendidikan Bidan. <http://www.jurnalpendidikanbidan.com> Diakses tanggal 16 Juli 2015

Gultom, 2009. Karakteristik Penderita Perdarahan Antepartum Yang Dirawat Inap di Rumah Sakit Santa Elizabeth Medan tahun 2004-2008. Skripsi Fakultas Kesehatan Masyarakat Universitas Sumatera Utara, Sumber :http://www.repository.ac.id

Harnia, 2010. Sikap dan Tindakan Bidan Terhadap Penanganan Retensio Plasenta di Desa Terjun Kecamatan Medan Marelan tahun. Skripsi D-IV Kebidanan Fakultas Keperawatan USU.sumber : http://www.repository.usu.ac.id

Hakimi, (2010). Ilmu kebidanan patologi dan pisiologi persalinan, Yogyakarta ejentia medica

Manuaba, 2010. Ilmu Kebidanan Penyakit Kandungan dan Keluarga Berencana Untuk Pendidikan Bidan, Penerbit EGC, Jakarta.

Nasution, 2012. Prevalensi Persalinan Seksio Sesarea atas Indikasi Plasenta Previa di RSUD Dr. Pirngadi Medan, sumber http://www.repository.usu.ac.id

Notadmodjo, 2010. Perilaku Kesehatan, Penerbit Rineka Cipta, Jakarta.

Petra, 2008. Kemampuan (Ability). http://digilib. petra.ac.id /viewer. Php ? page $=17 \&$ submit. $\mathrm{x}=14$ \&submit. $\mathrm{y}=17$ \&submit $\quad=$ next \& qual=high\&submitval =next\&fname $=\% 2$ Fjiunk pe $\% 2$ Fs $1 \% 2$ Feman $\% 2$ F2008\%2Fjiu nkpe-ns- s1-2008-31403361-9052-hanurdachapter2.pdf. Diakses pada tanggal 16 Juli 2015

Pratiwi, 2012.Retensio Plasenta, sumber :http://delvitapratiwi.blogspot.com 
Rohani dkk, 2011. Asuhan kebidanan Pada Masa Persalinan, penerbit Salemba Medika

Rukiyah \& Yulianti, 2010. Asuhan Kebidanan IV (Patologi) : CV Trans Info Media Jakarta

Sarwono, 2010. Ilmu Bedah Kebidanan. Jakarta : Yayasan Bina Pustaka Sarwono Prawirohardjo

Setiadi, 2007. Konsep dan Penulisan Riset Keperawatan, Penerbit Graha Ilmu.

Sunaryo. 2007. Psikologi untuk Keperawatan. Jakarta : EGC

Wawan \& Dewi, 2010. Teori \& Pengukuran Pengetahuan, Sikap dan Perilaku Manusia, Penerbit Nuha Medika, Yogyakarta.
Wiknjosastro,2010. Ilmu Kebidanan, Penerbit Yayasan Bina Pustaka Sarwono Prawirohardjo, Jakarta.

Winardi, Sunaryo. 2007. Psikologi Keperawatan. Jakarta. Salemba Medika

WHO, 2010. Maternal Health Epidemiology, sumber :http://who.int/maternal_childadolescent/epidemiology/maternal/en/index.htm 1. 